\title{
TOWARD A TYPOLOGY OF ARABIC DIALECTS: THE ROLE OF FINAL CONSONANTALITY*
}

\author{
Samira Farwaneh
}

\section{UNIVERSITY OF ARIZONA}

The salient constraint on Arabic stems is final consonantality which stipulates that the right edge of a stem must be marked by a consonant. In this paper, I examine the role of final consonantality as an extended prosodic constraint operating on syllables and moras, functioning as a parameter differentiating the main two dialectal types, onset and coda dialects. The effect of final consonantality is observed not only in specifying the site of epenthesis, but also in determining the distribution of prosodic rules such as gemination, degemination, and syncope as well as predicting the quality of the epenthetic vowel. The hypothesis is that extending final consonantality to the phonological component of the grammar in coda dialects is motivated by the desire to ensure uniformity between edges of prosodic and morphological constituents.

\section{Introduction}

The classification of Arabic dialects according to their structural characteristics has become an important area of research. A growing body of literature on dialect structure has shown that surface divergence among the dialects is an elusive manifestation of limited underlying structural patterns describable in terms of typological generalizations involving implicational statements. An implicational statement specifies that the presence of a certain structural feature implies the presence or absence of another, but not vice-versa. An example of a syllable-related implication is that if a language has closed CVC syllables, then it follows that it also has open CV syllables, but the reverse is not necessarily true. Syllable structure provides fertile grounds for a typological classification of the dialects in the literature, taking as its primary axis the position of epenthesis in medial clusters (Broselow 1983, 1992; Eid 1985; Farwaneh 1995; Itô 1989; Kiparsky 2003; Selkirk 1981). These accounts have observed that individual dialects show varying degrees of tolerance

\footnotetext{
*Many thanks are due to the JAIS reviewers whose helpful advice lead to the addition of more corroborating data to some sections in the paper which naturally contributed to its improvement. Any errors are the responsibility of the author.
} 
toward consonant clusters, which may arise for a number of reasons and from a number of sources. One source of potential clustering is morpheme concatenation, especially when consonant-final stems are augmented with consonantal affixes, e.g., /gil-t-l-ha/ 'I said to her', which creates four consonants that cannot be properly syllabified: /.gil. tl .ha./. Another process that potentially creates clustering is syncope, which deletes an unstressed high vowel in an open syllable, e.g., /yi-ktib-u/ ${ }^{1}>$ /yik.ti.bu/ > /yiktbu/ 'they write'. All dialects familiar to me agree on the repair mechanism available to rectify unwanted clusters, namely, epenthesis, but disagree on the position in the cluster where the epenthetic vowel is inserted. In a triconsonantal cluster CCC, an epenthetic vowel may be inserted after or before the second consonant, $\mathrm{CCvC}$ or $\mathrm{CvCC}$ (upper case $\mathrm{V}$ indicates an underlying vowel while lower case $\mathrm{v}$ indicates an epenthetic vowel). Variation in the site of epenthesis is determined by the syllabification pattern in the dialect. If the epenthetic vowel lands after the second consonant in the cluster, rendering it as the onset of an open syllable, the dialect is classified as an 'onset' or 'CV' dialect, illustrated as CCC $>$ C.Cv.C. Examples of onset dialects are Egyptian and Saudi (Makkan as described in Abu-Mansour 1987). On the other hand, inserting the epenthetic vowel before the second consonant to form a closed syllable, identifies the dialect as a 'coda' or 'VC' dialect, thus CCC > CvC.C, exemplified by the Levantine family, North African varieties and some Gulf dialects.

Previous works on dialect typology also revealed a number of crossdialectal generalizations correlating epenthesis site with the application or failure of phonological processes (see in particular Farwaneh 1995 and Kiparsky 2003). This paper will further examine the implicational power of the epenthesis site typology, arguing that the divergent epenthesis strategies and the asymmetric distribution of phonological processes in the two dialect types reveal a conspiracy effect aiming to bring outputs in conformity with syllable structure well-formedness constraints, particularly final consonantality which minimizes the number of weak vowel-final syllables and maximizes instead consonant

1 This morphemic division assumes a CCVC imperfective stem, based on empirical evidence and following other proposals (McOmber 1995, Benmamoun 1999, 2003). Although Classical Arabic and the regional varieties may share some morphological features, such as the CCVC stem, this by no means implies that Classical Arabic is the autonomous source from which regional Arabic evolved as dependent varieties. 
final ones. The notion of 'Conspiracy' was introduced to the phonological theory landscape in Kisseberth's revolutionary work on Yawelmani, where he observes that blocking and triggering of structure changing rules apply selectively only when the output of the rule is structurally compliant with the constraints of the language (Kisseberth 1970). For example, the constraint on consonant clusters in Yawelmani influences the application of several phonological changes with one goal in common: Avoid consonant clusters. In response to this constraint, a rule may delete a consonant $\mathrm{CCC}>\mathrm{CC}$; epenthesize a vowel $\mathrm{CCC}>$ $\mathrm{CvCC}$; or block addition of a consonant $* \mathrm{CC}>\mathrm{CCC}$. Thus, heterogeneous phonological changes like epenthesis, deletion or metathesis conspire to achieve a homogeneous target, the ban on triconsonantal clusters. ${ }^{2}$

Although Arabic dialects converge on prohibiting medial clusters as is the case in Yawelmani and many languages, avoiding clusters is but a part of a broader picture. Examining the co-occurrence or co-occurrence restriction holding among cluster-eliminating repair strategies such as syncope, epenthesis, gemination, and degemination in onset and coda dialects reveals a significant distributional pattern: Rules which destroy open syllables (syncope and degemination) are either nonexistent or apply within narrow limits in onset dialects, where the epenthetic vowel forms an open syllable. However, they apply frequently in coda dialects where the epenthetic syllable is closed or consonant-final. I suggest that this distributional difference is motivated by the expansion of the final consonantality constraint Final-C from a morphological constraint requiring stems to be consonant final (McCarthy and Prince 1990) to a prosodic constraints on syllables and in some dialects moras as well. In onset dialects where final consonantality is limited to stems, the unmarked open CV syllable is preserved unless its preservation violates another syllable structure constraint.

The discussion proceeds as follows: Section (1) gives an overview of the epenthesis site typology as discussed in the literature on Arabic dialect syllable structure, showing the correlation between medial and initial cluster epenthesis, and the constraints on syllable structure motivating this variation, with special emphasis on the role of final consonantality, the focus of the conspiracy in Arabic dialect typology. Section (2) addresses processes of reduction that apply broadly in Coda

\footnotetext{
2 For an extensive discussion of the conspiracy problem and its influence on the evolution of Optimality Theory see McCarthy 2002 chapters 2 and 3.
} 
dialects but are limited to one environment in onset dialects.

Section (3) examines the distribution of augmentation particularly gemination demonstrating the triggering effect of Final-C. Finally the discussion of the quality of the epenthetic vowel and its correlation with syllable type is the focus of Section (4), with Section (5) concluding the paper.

\section{Syllable structure constraints and epenthesis site}

This section begins with a brief survey of the empirical data based on which the onset/coda dichotomy has been established in earlier works cited in the introduction. I address the uniformity vs. variability of syllabification and the systematicity of epenthesis site in medial and initial clusters Section (1.1) after which the syllable structure wellformedness constraints guiding segment-to-syllable mapping and consequently constraints motivating epenthesis placement are discussed in Section (1.2).

\subsection{Syllable types and epenthesis site}

Various individual and contrastive descriptions of the dialects agree that all dialects permit the three basic syllable types: light monomoraic $\mathrm{CV}$, heavy bimoraic CVV and CVC. Dialects also converge on the mapping of internal segments into surface syllables with the exception of medial triconsonantal clusters. An intervocalic single consonant is invariably mapped as the onset of the second syllable; [ka.tab] not *[kat.ab]; in the case of two intervocalic consonants, they spread evenly across syllables; [mak.tab] not *[ma.ktab].

Variation arises when three medial consonants call for syllabification; while the first uniformly marks the right edge (coda) of the first syllable and the third the left edge (onset) of the final syllable, indeterminacy arises concerning the syllabic status of the medial consonant (second in the cluster): VCCCV > VC.(C)CV. Two epenthetic positions are available: Postconsonantal epenthesis places the medial consonant in an onset position VC.Cv.CV, while preconsonantal epenthesis places it in a coda position VC.vC.CV. This variation in the locus of the epenthetic vowel in triconsonantal clusters has been taken as the primary determinant of the dialect's type in earlier works (Broselow 1983, 1992; Selkirk 1981; Itô 1986, 1989, Farwaneh 1995, Kiparsky 2003). Following these works, I will continue to consider postconsonantal epenthesis as the primary property of the onset type, and preconsonantal epenthesis as the marker of the coda type. Below are examples from both dialect types showing the asymmetric location of epenthesis: 
(1) Epenthesis in medial clusters

Onset dialects: VCCCV > VC.Cv.CV

a. Egyptian (Broselow 1976)

katabt+lu katabtilu 'I wrote to him'

bint-na bintina 'our daughter'

b. Saudi (Abu-Mansour 1987)

tarjam-t-l-u tarjamtalu 'I translated for him'

Parditha Pardaha 'her land'

c. Sudanese (Hamid 1984, Trimingham 1946)

šuf-t-hin šuftahin 'I saw them-F'

bank-na bankana 'our bank'

Coda dialects: VCCCV > VC.vC.CV

a. Iraqi (Erwin 1973)

Pibn+na Pibinna 'our son'

gilt+la gilitla 'I told him'

kitabt+la kitabitla 'I wrote to him'

b. Abu Dhabi (Qafisheh 1977)

Sabd Sabidhum 'their slave'

šift+hum šifittum 'I saw them'

darabt+ha darabitta 'I hit her'

?asm+ha Pasimha 'her name'

Puxt+ha Puxutta 'her sister'

The two dialect groups transfer the same epenthesis strategy to initial clusters: postconsonantal epenthesis in onset dialects and preconsonantal epenthesis in coda dialects. The effect of this transfer is most visible in the treatment of borrowings. The examples in (2) are representative of both strategies:

(2) Epenthesis in initial clusters

Onset dialects: \#CCV > Cv.CV

a. Egyptian (Broselow 1983)

fired 'Fred'-name silayd 'slide'

siweter 'sweater' bilastik 'plastic'

b. Saudi (Abu-Mansour 1991)

farank 'Frank'-name balastik 'plastic'

c. Sudanese (Trimingham 1946)

kulub 'club'

karīma 'cream'

Coda dialects: \#CCV > vC.CV

a. Iraqi

člāb ičlāb 'dogs'

drūs idrūs 'lessons' 


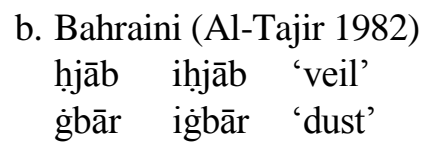

This variability in the positioning of epenthesis was not only evident in L1 phonology, but, as observed in Broselow (1983), was also transferred into L2 phonology, thereby producing divergent surface forms such as [filoor] and [istirīt] vs. [ifloor] and [sitrīt] among Egyptian and Iraqi learners of English respectively. The convergence among dialects on the syllabification of intervocalic one or two consonants vs. the variability in the syllabification of three intervocalic and two initial consonants on the one hand, and the systematicity of epenthesis placement in each dialect on the other are attributable to a number of syllable structure markedness constraints discussed in the following section. These constraints, particularly final consonantality (final-C), will establish the foundation for explaining the scope of augmentation and reduction processes discussed in Section (2) and (3).

\subsection{Constraints on syllabification}

The consensus among dialects on syllabifying VCV and VCCV sequences indicate the effect of two crucial constraints that guide the mapping of open $\mathrm{CV}$ and closed CVC syllables in all the dialects. These two constraints are introduced with their definitions in (3):

(3) Constraints on syllable structure

a. Onset: All syllables must have onsets (Itô 1986).

b. Coda moraicity: coda consonants are assigned independent moras or timing units (Hayes 1989).

The onset constraint bans vowel-initial syllables; thus, all syllables must begin with a consonant. The coda moraicity constraint maximizes the weight of a syllable to two timing units by assigning a coda position to a postvocalic consonant wherever possible; this is necessary in quantity sensitive languages to differentiate for stress purposes between light monomoraic and heavy bimoraic syllables. These two constraints make syllabification of one and two intervocalic consonants uniform across the dialects: a VCCV sequence is syllabified as VC.CV satisfying both constraints; a VCV sequence is syllabified as V.CV not *VC.V giving the onset constraint precedence over coda moraicity.

We focus now on the divergent syllabification patterns of internal VCCCV sequences with three consonant clusters. The literature on Arabic syllabification offers different theoretical treatments: The degenerate syllable camp, spearheaded by Selkirk's (1981) work, 
attributes the positional variability of epenthesis to a parameter stipulating the onset or coda position a stray consonant is assigned to. This view was later implemented in Abu-Mansour $(1990,1991)$ and expanded in Broselow (1992). The second camp (Itô 1986, 1989; Farwaneh 1995), resorts to the directionality parameter and its variable settings to account for the same problem. Rightward (Onset dialects) or leftward (Coda dialects) syllabification places the epenthetic vowel when needed in its proper location.

Whether it is the directionality, degenerate syllable or Kiparsky's mora licensing parameter that determines epenthesis site, the main result is that in coda dialects epenthetic syllables end in a consonant, while in onset dialects epenthetic syllables mirror the unmarked syllable in the language. This outcome can be captured in the form of an alignment constraint requiring the right edge of all syllables in coda dialects to be occupied by a consonant. A formulation of the constraint appears in (4):

(4) Coda dialects

Final-C: All syllables must end in a consonant.

The Final-C constraint can be viewed as an extension of the well-known final consonantality constraint proposed in McCarthy and Prince (1990) requiring all stems to end in a consonant, whose effect is visible in all dialects, with the exception of weak vowel-final stems like [rama] 'throw'. In coda dialects, then, the scope of final consonantality is extended to cover prosodic constituents particularly syllables in addition to morphological constituents. In contrast, final-C in onset dialects is limited to stems and does not extend to syllables; in other words, final-c is limited to the morphological domain only. The absence of Final-C from the prosodic domain in onset dialects not only allows the unmarked $\mathrm{CV}$ syllable to emerge as a product of basic syllabification, but also to be preserved by blocking phonological processes that eliminate open syllables. Thus, phonological processes conspire to preserve open syllables in onset dialects while ensuring a consonant alignment of syllable edges in coda dialects in conformity with Final-C.

An alternative proposal appears in Broselow (1992) following Itô (1986) introducing a bimoraicity constraint which sets an upper and lower limit on syllable size, favoring bimoraic CVV and CVC syllables over undersized monomoraic $\mathrm{CV}$ or oversized trimoraic CVVC or CVCC syllables. Based on the behavior of syllable-related phonological rules such as syncope and epenthesis, she argues that such rules operate so as to maximize bimoraic syllables in obedience to the bimoraicity constraint. Thus, although Broselow does not make specific reference to conspiracy, rules in her proposal conspire to maximize syllables to 
bimoraicity. Since all Arabic dialects are quantity sensitive, the bimoraicity constraint cannot undertake the task of explaining the dialect typology. Preserving the weight distinction between CV and CVV/CVC syllables required for stress occurs in all dialects. For the purpose of syllable structure, however, dialects make a different type of distinction: The distinction is between open vs. closed syllables, rather than light vs. heavy as is the case in the stress system.

Epenthesis facts draw the line between dialects that favor onsets (open syllables) vs. those that favor codas (closed syllables) along the lines drawn by the final-C constraint in (4). I will show in Sections (2) and (3) below that the distribution of syllable-related phonological rules mirrors this division. Phonological rules destroy open syllables to maximize the number of closed syllables irrespective of their weight in coda dialects, whereas in onset dialects, elimination of open syllables is minimized.

\subsection{Typological observations}

In the absence of a final-C constraint on syllables in onset dialects, the first option is to generate open syllables, since this is the unmarked type; generating closed syllables is an option taken only if the nucleus is followed by another segment that requires syllabification, and cannot syllabify as the onset of a following vowel, in which case it takes a coda position as required by the coda moraicity principle. We take the optimal syllable in this group to be the open [CV] type, with the construction of closed syllables being contingent upon the presence of a postvocalic consonant. We may summarize the functioning of syllabification in onset dialects in (5)

(5) Onset dialects:

a. Construct an open syllable.

If a postvocalic consonant is present, then:

b. Construct a closed syllable.

In a coda dialect, Final-C delimits right edges of all syllables with a consonant; as a constraint, this type favors consonant-final syllables whenever possible. The optimal syllable in this group, then, is the closed syllable. An open syllable is constructed only if coda formation fails. The functioning of syllabification in the coda group is summarized in (6):

(6) Coda dialects

a. Construct a closed syllable.

If a postvocalic consonant is absent, then:

b. Construct an open syllable.

A number of phonological processes operative in the dialect, such as 
gemination, degemination, syncope, and epenthesis, have been analyzed as separate processes, obligatory but unrelated. However, the data I have collected show that syllable-related processes collaborate as a unit to serve a certain output target. As the discussion below will reveal, coda dialects impose a prohibition on non-final CV syllables. That is, if open syllables emerge in surface representations, they are usually relegated to word edges, e.g., [.ka.tab.] and [.niz.lu.]. The Final-C constraint bans open vowel-final syllables in any position; peripheral syllables are retained because of other constraints, such as the ban on initial consonant clusters or the preservation of vocalic affixes.

The advantage of the Final-C constraint over other constraints referring to syllable size such as the bimoraicity constraint mentioned above is that it forces the choice of closed syllables of any weight over open (codaless) syllables. Closed syllables may be bi- or monomoraic, as the discussion of the Levantine data in Section (2.1) below illustrates. As a response to the Final-C constraint, phonological rules conspire to eliminate medial vowel-final syllables wherever possible. Two strategies are available to ensure obedience to final-C: A reduction strategy eliminating open syllables and resyllabifying the stranded consonant after readjusting its moraic status if need be, or an augmentation strategy complementing open syllables with a coda consonant. Each strategy will be discussed in turn in the following sections. Section (2) focuses on reduction processes including syncope and degemination, showing that Final-C motivates reduction in various environments in coda dialects while in onset dialects reduction is limited to one environment where two successive light syllables may occur. Section (3) addresses augmentation processes explaining their limited applicability to coda dialects in conformity to the Final-C constraint.

\section{Reduction}

Elimination of an open syllable is ensured, either by deleting the nucleus of the syllable (syncope) discussed in (2.1), or by erasing the onset consonant if it constitutes the second half of a geminate (degemination) the focus of Section (2.2).

\subsection{Syncope}

Syncope, which has been discussed extensively in the literature on Arabic dialects, deletes a short unstressed high vowel in a number of environments, particularly in double sided open syllables (VC_CV) attested in most if not all dialects. The case frequently cited to exemplify the operation of this rule is the case of the inflected forms of the perfective verb. In many onset and coda dialects, inflection of verbs with 
a high stem vowel like /nizil/ 'leave' with the plural nominative affix /-u/ (e.g., Egyptian and Levantine), or /-aw/ (e.g., Iraqi and Gulf) renders a sequence of three open syllables [.ni.zi.lu.] exposing the medial /i/ as a target for deletion. More examples are presented in (7):

(7) Egyptian/Levantine

$\begin{array}{lll}\text { He } & \text { They } & \text { Gloss } \\ \text { Yímil } & \text { Yímlu } & \text { 'did' } \\ \text { fíhim } & \text { fíhmu } & \text { 'understood' } \\ \text { xísir } & \text { xísru } & \text { 'lost' } \\ \text { símiৎ } & \text { sím@u } & \text { 'heard' }\end{array}$

Kenstowicz (1980) gives other examples where /i/ is syncopated in double-sided open syllables. The prefixal vowel /i/ of the person marker /yi/ is deleted when preceded by the present tense marker /bi/ and followed by a CV sequence as in /bi-yi-zūr/ > [biyzūr] 'he visits'. Similarly, the second vowel in the seventh and eighth verbal measures deletes when amalgamated with a vowel-initial suffix, e.g., /bi-yi-n-bișitu/ > [biyinbiștu] 'they enjoy themselves'. I have not come across a dialect where syncope of a high vowel does not apply in this environment. Another example of medial high vowel syncope is the loss of the initial /i/ of the feminine marker /it/ which marks feminine nouns in an $i d \bar{a} f a$ after affixation of a vowel-initial suffix:

(8) Levantine

\begin{tabular}{|c|c|c|}
\hline . /madrasit-u/ & [madrástu] & 'his school' \\
\hline & [maktab & 'his library' \\
\hline & {$[\mathrm{mu}$} & olem' \\
\hline b. /wazīrit-u/ & [wazīrt & nister' \\
\hline /ra?īsit-u/ & [rapī & siden \\
\hline /makānit-u/ & [makāntu] & his rank' \\
\hline
\end{tabular}

Finally, the rule likewise applies to the feminine of nominal and participial forms of the shape CVVCiC-a: ${ }^{3}$

(9) Levantine/Saudi

$$
\begin{array}{lll}
/ \text { kātib-a/ } & {[\text { kātba }]} & \text { 'writing-f' } \\
\text { /sāmiS-a/ } & \text { [sāmSa }] & \text { 'listening-f' }
\end{array}
$$

Morphological concatenation of the affix to the stem renders the previously extrasyllabic (stem-final) segment intrasyllabic.

3 Lexicalized nominals are usually blocked from undergoing syncope thereby producing minimal pairs exhibiting i/0 alternation, e.g., [šāGira] 'poet-F' vs. [šāYra] 'feeling-F'; [kātiba] 'author-F' and [kātba] 'writing-F'; [țaāliba] 'student-F' and [țaālba] 'seeking-F'. 
Syllabification of stem-final segments will then open the preceding syllable rendering its nucleus susceptible to syncope, which deletes unstressed high vowels in open syllables by deleting their melodic features, thereby leaving a stranded onset behind: /.ni.zi.lu./ > [.ni.z.lu.]. In all the syncope cases presented above, the stranded consonant resulting from syncope can be housed within the preceding syllable. If the vowel bordering the syncope site is short [CV.C_.CV.], the consonant can be syllabified as a coda of the preceding syllable as dictated by the coda moraicity constraint, .CVC.CV., e.g., /nizil-u/ > /.ni.z_.lu./ > [niz.lu]. If the preceding vowel is long [.CVV.C_.CV.], then the segment is adjoined to the preceding long nucleus to serve as its coda, .CVVC.CV., e.g. /.kā.ti.ba./ > /.kā.t_.ba./ > [.kāt.ba.]. Dialects intolerant of the so-called superheavy CVVC syllable repair the intolerable syllable by vowel shortening, [kat.ba], as in Egyptian. This type of syncope, which leaves behind a segment that can be incorporated in the existing syllable structure is what Broselow (1992:30) refers to as 'structure preserving syncope', and as the preceding examples show, it always involves unstressed high vowel syncope in double-sided open syllables, which applies in both dialect groups. I now turn to syncope cases specific to coda dialects.

A second type of syncope, which Broselow terms 'non-structure preserving', yields an unsyllabifiable segment which cannot be housed in an already existing syllable. This occurs when syncope deletes a high vowel in a single-sided open syllable (CC_CV). The remaining consonant appears as a coda of an epenthetic vowel. The examples in (10) are collected from Broselow (1992), McCarthy (1986), Fischer and Jastrow (1980), and Shāban (1977 representing Levantine, Iraqi, Bahraini, and Omani:

(10) Non-Structure Preserving Syncope

$\begin{array}{lll}\text { a. Verbs } & & \\ \text { He } & \text { They } & \text { Gloss } \\ \text { yiktib } & \text { yíkitbu } & \text { 'write' } \\ \text { ytarjim } & \text { ytarijmu } & \text { 'translate'4 } \\ \text { yuḍrub } & \text { yuḍurbūn } & \text { 'hit' }\end{array}$

\footnotetext{
4 The homophonous affixes /-u/ '3pl-subject' and /-u/ '3sg-m-object' render the first two verbs [yikitbu] and [yitarijmu] ambiguous, encoding as 'they verb' or 'he verb it-M'.
} 
b. Nouns

$$
\begin{array}{lll}
\text { Stem } & \text { Possessive } & \text { Gloss } \\
\text { bádle } & \text { bádiltu } & \text { 'suit' } \\
\text { gurfe } & \text { guruftu } & \text { 'room' }
\end{array}
$$

Concatenation of the vowel initial suffix /u/ opens the medial syllable rendering it a target for syncope, [.yik.ti.bu.] and [.bad.li.tu.]. But deleting the medial /i/ leaves a consonant whose accommodation within the existing syllable is bound to result in impermissible clustering in some dialects 5 , /.yikt.bu/ and /.badl.tu./. The only repair strategy left is to erect a new syllable to house the homeless consonant yielding the surface [yikitbu] and [badiltu]. This type of syncope followed by epenthesis is absent in onset dialects because, as Broselow (1992) points out, the output of syncope cannot be syllabified in a manner consistent with the syllabic constraints of the dialect. The only way to syllabify the residue of syncope in /.yik.t.bu./ is to construct another open syllable with an epenthetic vowel to replace the open syllable just deleted, and so syncope is blocked in this environment.

'Non-structure preserving syncope' may also apply to the nucleus of initial syllables in coda dialects, the deletion of which creates onset clusters. Many Levantine dialects syncopate the initial unstressed vowel in the $1^{\text {st }}$ and $2^{\text {nd }}$ person conjugation of Form I verbs as in (11):

(11) Levantine

$\begin{array}{lll}\text { He } & \text { You/I } & \text { Gloss } \\ \text { fíhim } & \text { fhímt } & \text { 'understood' } \\ \text { Šírib } & \text { šríbt } & \text { 'drank' } \\ \text { símiৎ } & \text { smíSt } & \text { 'heard' } \\ \text { nízil } & \text { nzílt } & \text { 'descended' }\end{array}$

Like medial syncope in [yiktbu], initial syncope in the forms above leaves behind a segment that cannot be syllabified because it is not preceded by a vowel to which it can serve as a coda. In onset dialects, the output of syncope will be repaired by epenthesis, which generates an output identical to the input of syncope as shown in the derivation (12). Therefore syncope in this environment is blocked in this group, as expected.

(12) Onset dialects

/fihim-t/ syncope $>*[$ fhimt $]$ epenthesis $>$ [fihimt]

5 Some Levantine and North African dialects allow coda clusters of equal sonority such as $/ \mathrm{kt} / \mathrm{in}$ which case epenthesis is not needed. 
There are other options, however, to which a dialect could resort in order to eliminate monomoraic CV syllables without jeopardizing syllable structure constraints. I will show in what follows that these options are limited to coda dialects, and I will conclude later that the absence or restriction of reductive phonological rules in onset dialects is indeed for the goal of preserving, not eliminating, open syllables.

A dialect may maximize the application of syncope by extending its target to low vowels. This option is observed in what is termed nondifferential dialects like Syrian and Iraqi, where syncope deletes both high and low vowels in double-sided open syllables. In Syrian, the feminine output of Form I perfective verbs exemplifies low vowel syncope:

(13) Syrian

$\begin{array}{lll}\text { He } & \text { She } & \text { Gloss } \\ \text { kátab } & \text { kátbit } & \text { 'wrote' } \\ \text { fátah } & \text { fáthit } & \text { 'opened' } \\ \text { Pátal } & \text { Pátlit } & \text { 'killed' }\end{array}$

Iraqi is another non-differential dialect that deletes medial vowels of any height in medial open syllables. In addition, Iraqi, like other Bedouin dialects, raises low vowels in nonfinal open syllables.

(14) Iraqi

$\begin{array}{llll}\text { He } & \text { She } & \text { They } & \text { Gloss } \\ \text { kítab } & \text { kítbat } & \text { kítbaw } & \text { 'wrote' } \\ \text { ríkab } & \text { ríkbat } & \text { ríkbaw } & \text { 'rode' } \\ \text { túbax } & \text { țúbxat } & \text { țúbxaw } & \text { 'cooked' } \\ \text { Púkal } & \text { Púklat } & \text { Púklaw } & \text { 'ate' }\end{array}$

Derivation of [kítbat] proceeds as in (15):

(15) $/ \mathrm{kitab} />$ [kitbat]

a. Underlying stem: /katab/

Syllabification: $\quad$.ka.ta.(b) ${ }^{6}$

Syncope: N/A

Raising: $\quad$ ki.ta.(b) Surface: [kítab]

b. Underlying form: /kitab-at/

Syllabification:. ki.ta.ba.(t)

6 All theories of syllabification agree that a final consonant is extrasyllabic, that is, it lies outside the syllable boundary, hence it does not contribute to the weight of the syllable. It follows then that internal CVC counts as heavy or bimoraic and attracts stress while word-final CVC is light or monomoraic and thus escapes stress placement. 
Syncope: $\quad$ ki.t.ba.(t)

Raising: N/A

Resyllabification: .kit.ba.(t) Surface: [kítbat]

Deleting medial /a/ in the two dialects yields a stray consonant that can be incorporated within the preceding syllable as a moraic coda. If medial syncope is applicable in both dialect groups, and if preference toward bimoraic syllables should exist in both groups, then we need to explain why this strategy, i.e., non-differential syncope, is not utilized in onset dialects. We contend that the preservation of the unmarked non-weak (open CV) syllables blocks the application of non-differential syncope, whose effect in coda dialects is attributable to the active final-C constraint. The following table (16) summarizes the difference in the application of the syncope rule between coda and onset dialects in terms of the target and environment of the rule:

(16) Syncope in onset and coda dialects

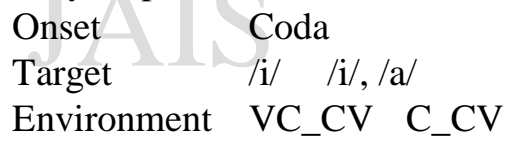

\subsection{Degemination}

Another strategy that helps minimize the number of surface open syllables is degemination, under circumstances where epenthesis in open syllables would otherwise occur. Geminate consonants are analyzed underlyingly as a single consonant (Hayes 1989, McCarthy and Prince 1986, 1990) doubly-linked to the final mora of one syllable and the syllable node of the following syllable, as in (17):

(17) Surface geminates

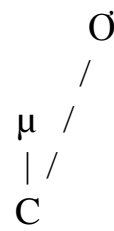

Surface geminates are always heterosyllabic, with one half of the geminate serving as the coda of one syllable, and the second as the onset of a following syllable. In onset dialects, the second syllable is obligatorily filled by epenthesis. The following examples in (18) are from Egyptian. When a word with a final geminate is inflected with a consonant-initial suffix, epenthesis intervenes between the stem geminate and the suffix. Epenthetic vowels in Egyptian behave on par with input vowels with respect to stress assignment. As all the examples in (18) show, the penultimate syllable is stressed even though it is 
epenthetic: ${ }^{7}$

(18) Egyptian

$\begin{array}{lll}\text { Stem } & \text { Inflected } & \text { Gloss } \\ \text { kúll } & \text { kullúhum } & \text { 'all of them' } \\ \text { Cádd } & \text { Gaddúhum } & \text { 'he counted them' } \\ \text { Sáff } & \text { Saffína } & \text { 'our class' } \\ \text { Púmm } & \text { Pummáha } & \text { 'her mother' }\end{array}$

Conversely, a geminate is subject to simplification or degemination in coda dialects by reducing it to a surface single consonant. ${ }^{8}$ The following forms are from Levantine:

(19) Levantine

$\begin{array}{lll}\text { Stem } & \text { Surface } & \text { Gloss } \\ \text { kull } & \text { kúlhum } & \text { 'all of them' } \\ \text { Pimm } & \text { Pímna } & \text { 'our mother' } \\ \text { radd } & \text { rádhum } & \text { 'he returned them' }\end{array}$

Some coda dialects, like Abu Dhabi exemplified in (20) below, allow two surface variants, one with degemination and one with epenthesis (Qafisheh 1977:34): ${ }^{9}$

7 The default epenthetic vowel is /i/ which harmonizes with the following affixal round vowel (kulluhum) and lowers to /a/ in harmony with a following affixal low vowel if the intervening consonant is a guttural (kullaha but kullina).

8 Abu-Salim (1980) claims that there is length distinction between surface tautosyllabic geminate and single consonants. He cites as evidence minimal pairs such as [Garabna] 'our Arabs' and [Garabbna] 'on our God'. Obrecht (1965) also contends that native speakers perceive a length contrast between geminates and nongeminates. Many studies on Arabic, however, follow the general assumption that tautosyllabic geminates are reduced by degemination (see for example Qafisheh 1977:22), thereby neutralizing forms with underlying geminates with those containing underlying single consonants, e.g., [kul] 'eat!' (from /'akal/), and [kul] 'all' (from /kull/).

9 According to Qafisheh (1977:34ff.) stress falls on penultimate syllables regardless of weight, yielding a stress pattern similar to that of Egyptian, e.g., [madrása] 'our school', [maktába] 'our library', [minkísir] 'broken'. Thus, in biliteral forms stress is assigned to the epenthetic syllable following the geminate, e.g., [killíhum] 'all of them', [gașsáhum] 'he cut them'. The optionality of degemination in this case can therefore be attributed to the stressing of the epenthetic vowel. In dialects (like Levantine) that stress antepenultimate syllables preceding the geminate, e.g., [.kúl.1_.hum], degemination seems obligatory. 
(20) Abu Dhabi

$\begin{array}{lll}\text { Form 1 } & \text { Form 2 } & \text { Gloss } \\ \text { killíhum } & \text { kílhum } & \text { 'all of them' } \\ \text { gașșáhum } & \text { gáșhum } & \text { 'he cut them' }\end{array}$

The first half of the geminate is already syllabified as the coda of the preceding syllable. Thus, degemination can safely eliminate the open syllable formed by the second half of the geminate without generating unsyllabifiable segments. Yet we find that while degemination is widely applicable in coda dialects, it is mysteriously absent in onset dialects. If syllabification is guided by the tendency to maximize syllables to bimoraicity in both dialect groups, then one would expect that the dialects would converge on eliminating monomoraic open syllables by degemination.

As seen from the preceding discussion, the distribution of syncope and degemination is asymmetric, applying widely in coda dialects to all open syllables, unless such deletion would result in an impermissible cluster or a subminimal word. In contrast, onset dialects limit their options of monomoraic syllable reduction to one strategy, namely, syncope in double-sided open syllables. One may argue that reduction is blocked if its output cannot be syllabified in a manner consistent with the syllable constraints of the dialect. However, I have discussed two strategies for open syllable erasure, whose outputs are perfectly syllabifiable. These options are listed below:

a. Non-differential syncope: Extending the target of syncope in VC_CV environments to low vowels, e.g., /katabet/ > [kátbet], as in Syrian.

b. Degemination: deletes the second syllabic position resulting from syllabification of geminates, e.g., /.kil.l-.hum./ > [.kíl.hum.]

\section{Augmentation}

The second strategy employed by the dialects to minimize open syllables is via syllable augmentation. Instead of deleting monomoraic open syllables, they may be augmented by assigning a second empty mora or timing unit to the syllable, rendering it heavy. This empty mora is available for spreading from the right by geminating the following consonant; a strategy limited to coda dialects only.

All cases of gemination attested in the dialects apply in a perfectly well-formed syllabic environment; in other words, one cannot invoke a syllable structure constraint to explain the applicability of gemination. We assume, then, that the motivation behind this process is the elimination of open syllables wherever they may be found. One source of 
surface open syllables is morphological concatenation, examples of which are discussed below.

In Omani, the inflected form of the third person singular of the active participle is formed by infixing the morpheme /in/ between the active participle stem and the pronominal suffix. ${ }^{10}$ The following forms in (22) are from Shāban (1977:58 ff.):

(22) Omani Underlying

a. nasyān-ha

Surface

Gloss

b. tārik-hum nasyānínha

'he has forgotten her'

c. samৎān-u

tārkínhum

'he is leaving them'

d. tārik-u samৎānínnu

'he is listening to him'

e. sāriq-u tārkínnu 'he is leaving him' sārqínnu 'he has robbed him'

Syllabification of the output in (22a) yields no medial open syllables and hence requires no recourse to deletion or augmentation, e.g., [.nas.yā.nin.ha.]. In (22b), on the other hand, syllabification yields one medial open syllable eliminated by syncope, e.g., /.tā.ri.kin.hum/ > [.tār.kin.hum.]. In (22c), however, the resulting open syllable is eliminated by augmentation, [.sam.โā.nin.nu.], ${ }^{11}$ rather than the expected reduction by syncope - given the vulnerability of high vowels in open syllables - yielding the unattested *[.sam.Yān.nu.]. Syllabification of the form in (22d) renders two successive open syllables with high nuclei. In this case, the first is syncopated while the second is adjusted by

10 It is not clear what exactly the function of the intervening particle /in/ is. Shāban suggests that it may be a remnant of the genitive marker (tanwin) of Standard Arabic (Shāban 1977:86). This is supported by the fact that the tanwin in SA marks the verbal function of the active participle, as opposed to its nominal function as the first noun of a construct phrase; e.g., [kātibun alkitāba] 'writing the book' vs. [kātibu lkitābi] 'writer of the book'. Eksell (1984) provides an insightful yet still indeterminate account of the -in- interfix in which the Classical tanwin constitutes one stage of its development; the reader is referred to this article for a better understanding of this intriguing morphological phenomenon of Bedouin Arabic.

11 The particle /in/ does not affix to the plural form of the active participle which is formed by concatenation of the plural marker /-īn/. Thus we find /sāriqīn-u/ > [sārqīnu], and /sāriq-īn-ha/ > [sārqīnha] (Shāban 1977:86). This absence evidences a case of haplology prohibiting successive identical syllables * [sārqīninnu] similar to that observed in English in forms such as feminine-ism $>$ feminism not $*$ femininism. 
gemination. The derivation of [sārqinnu] appears in (23):12

(23) /sāriq-in-u/
Input:
/sariq-in-u/
Syllabification: sā.ri.qi.nu
Syncope: sār.qi.nu
Gemination: sār.qin.nu

A second case of gemination involves the final /t/ of the 3FS agreement marker when followed by a vowel-initial affix in Tunisian, e.g., /ktb-ət$\mathrm{u} />$ [kətbəttu] 'she wrote it-M'. Derivation of such forms proceeds as in:

(24) Tunisian

$\begin{array}{ll}\text { Input: } & \text { /ktb-ət-u/ } \\ \text { Syllabification: } & \text { [.kt.bə.tu.] } \\ \text { Gemination: } & \text { [.kt.bət.tu.] }\end{array}$

Gemination in this case seems motivated by Final-C constraint which favors consonant-final syllables. The affixal /t/ which occupies a coda position in [.kt.bət.] retains its coda position in [.kt.bət.tu] by gemination, thus avoiding a medial open syllable.

Fischer and Jastrow (1980:256) cite a few examples of gemination in Algerian and Tunisian where the addition of a vowel-final prefix or vowel-initial suffix triggers gemination of the consonant bordering the vowel. Both dialects employ the syncope and epenthesis combination to eliminate medial open syllables in verbal and nominal forms parallel to the Levantine and Gulf examples in (10) above; as in [.yi.lib.su] from /.yil.bi.su/. The application of the syncope/epenthesis pair closes the medial syllable at the expense of opening the initial syllable of the prefix. The scope of the Final-C constraint in the Eastern dialects (Levantine and Gulf) seems limited to non-peripheral syllables. But in the Western dialects, it extends to the initial syllable as well; exempting only final syllables from this consonantal alignment requirement. Therefore, the output of syncope/epenthesis is subjected to gemination to provide a coda closing the initial syllable. Gemination is applicable in both verbs and nouns, the derivation of [yeḍárbu] 'they hit' and [raqqəbti] 'my neck' (data from Fischer and Jastrow 1980:256) is

12 The derivational table is for illustration only; it is not meant to imply faithfulness to serialist models of generative phonology. A generative model assuming no rule ordering as proposed in Koutsoudas, Sanders and Noll (1974) or a non-derivational model such as Optimality Theory (Prince and Smolensky 1993) are capable of deriving the correct results. 


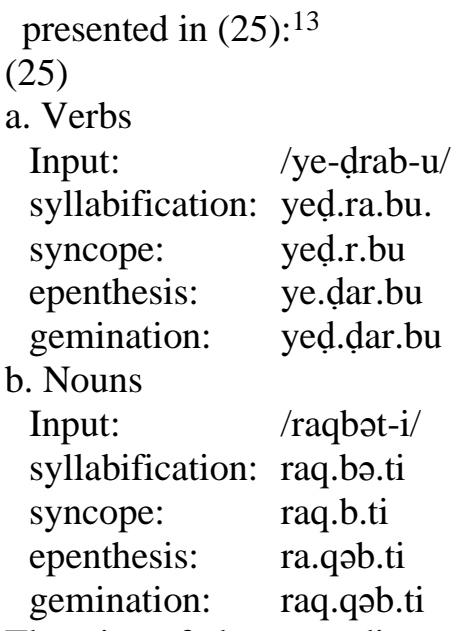

The aim of the preceding discussion was to show that augmentation processes are limited to coda dialects, a distributional property that I attribute to the expansion of the Final-C constraint to syllables. Since Final-C entails coda preference, then resyllabification of the coda with the following vowel destroys the preferred coda pattern of the dialect. The best strategy in this case is to geminate the coda, thereby preserving its coda status and at the same time providing an onset for the following vowel. Onset dialects, on the other hand, may resyllabify the coda as the onset of a following vowel and still remain true to their onset pattern that favors the unmarked open syllable; therefore gemination is unnecessary in this case. Application of gemination to peripheral syllables in Western dialects indicate that these varieties constitute the extreme case of final consonantality, where open syllables are banned except in final position.

In summary, whenever resyllabification after morphological concatenation generates a nonperipheral open syllable (and in Western dialects an initial syllable), a violation of Final-C constraint ensues. Such syllables are eliminated by reduction or repaired by augmentation. However, as the discussion in Sections (2) and (3) has shown, this constraint is operative only in coda dialects. Final-C is not at work in the phonology of onset dialects. The evidence for this conclusion is the absence of degemination and augmentation in this group. The absence of monomoraic syllable deletion rules cannot always be attributed to

13 I would like to thank Michael Carter for bringing my attention to the Fischer and Jastrow reference; the data therein seem to corroborate the analysis presented in this paper. 
unsyllabifiability, since the segments resulting from some of these operations can be properly syllabified. The outputs of non-differential syncope and degemination are perfectly syllabifiable; yet the two processes are absent in onset dialects.

Furthermore, it is not always the case that monomoraic open syllables are deleted in order to be replaced by bimoraic syllables for the purpose of attracting stress. As we have seen from the examples in (11) from Levantine discussed above, /yi-ktib-u/ > [.yík.it.bu], syllabification erases the internal open syllable /.ti./ and generates instead another monomoraic but closed syllable /.it./. Thus, stress remains unchanged, /yíktibu/ > [yíkitbu]; but syllable structure is improved to match the preferred coda pattern of the dialect.

Before closing this section, it is worth noting that Kiparsky's (2003) work based on extensive empirical coverage of 15 dialects adopts a more complex typology based on a semisyllable trichotomy: CV corresponding to Onset dialects where semisyllables are never licensed, VC corresponding to Coda dialects where semisyllables are licensed lexically, and $\mathrm{C}$ dialects where semisyllables are licensed lexically and postlexically. This latter type encompasses the North African dialects with tendency to consonant clustering. The typological generalizations he derives (149-150) demonstrate clearly that prosodic rules such as high-vowel syncope and assimilation-derived gemination do not differentiate between $\mathrm{VC}$ and $\mathrm{C}$ dialects. Therefore, one can maintain that the $\mathrm{VC}$ and $\mathrm{C}$ types belong to the Coda dialect group differing only postlexically. A dichotomy of Onset and Coda groups guided by final consonantality is sufficient to derive his generalizations.

The effect of final consonantality extends beyond predicting the distributional pattern of structure-changing rules to determining the quality of epenthetic nuclei, as will be discussed in the next section below.

\section{Epenthesis site and the quality of epenthetic vowels}

In agreement with previous theories of syllabification (Selkirk 1981, Itô 1986, 1989, Broselow 1992), the analysis developed here takes epenthesis to be an integral part of syllabification. Syllabification rules form syllables with empty nuclei to house unsyllabified segments. The position of the underspecified vowel is determined by the Final-C constraint. According to Archangeli's (1984) theory of underspecification, the quality of the epenthetic vowel is assumed to be the by-product of a set of language specific redundancy rules which fill in empty nuclei with the segmental features of the default vowel in the 
language. The default vowel is a segment present in the vowel inventory of the language. Thus, cross-linguistic differences in the quality of epenthetic vowels follow from arbitrary selection of different default vowels. As such, epenthetic vowels are not expected to participate in the phonology, except as target of low level assimilation rules which change the vowel quality under the influence of neighboring segments. However, the distribution of the low epenthetic vowel /a/ points to a strong correlation between syllable structure and vowel quality. This correlation is inextricably linked to the final consonantality constraint. I will begin with an examination of the distribution of epenthetic / $\mathrm{i} /$, which is the preferred epenthetic vowel. I will then compare the distribution of epenthetic /i/ with the distribution of epenthetic /a/.

\subsection{Distribution of non-low epenthetic vowels}

Epenthetic non-low vowels show a greater range of distribution than their low counterparts. All coda dialects which insert epenthetic vowels preconsonantally select a non-low vowel to fill in the empty nucleus, either/i/ in many dialects or / $/$ / in Syrian and North African dialects. One onset dialect, Egyptian, also selects /i/ as the default, hence epenthetic vowel. The following are examples from both dialect types:

(26)

a. Coda dialects:

$$
\begin{array}{lll}
\text { /jisr-na/ } & \text { jísírna } & \text { 'our bridge' } \\
\text { /Rakl-na/ } & \text { Pákilna } & \text { 'our food' } \\
\text { /Ribn-na/ } & \text { Píbinnna } & \text { 'our son' } \\
\text { /himl-na/ } & \text { híminlna } & \text { 'our load' } \\
\text { b. Egyptian: } & \\
\text { /gisr-na/ } & \text { gisrína } & \text { 'our bridge' } \\
\text { /Rakl-na/ } & \text { Paklína } & \text { 'our food' } \\
\text { /Ribn-na/ } & \text { Pibnína } & \text { 'our son' } \\
\text { /himl-na/ } & \text { hịmlína } & \text { 'our load' }
\end{array}
$$

Thus, epenthetic non-low vowels may occur freely in closed as well as in open syllables, but notice that the open epenthetic syllable in Egyptian is stressed. It would be interesting if a survey of epenthesis across the dialects reveals no epenthetic pattern with an unstressed epenthetic high vowel in an open syllable, for example, *[jísrina].

\subsection{Epenthetic low vowels}

The number of dialects that utilize the low vowel as an epenthetic vowel is very small. In fact, among the Arabic dialects examined, only two dialects, Saudi and Sudanese, favor low vowels. Epenthesis in Sudanese 
is needed only when a geminate or homorganic cluster comes in juxtaposition with another consonant, e.g., /Pumm-na/ > [?úmmana], and /bank-na/ > [bánkana]. ${ }^{14}$ In Saudi, moreover, two distinct epenthetic vowels are employed: Epenthetic /a/ is inserted postconsonantally to break up word-medial clusters, whereas epenthetic /i/ is inserted preconsonantally to break up word-final clusters. The examples in (27) show the distribution of /a/ and /i/ in Saudi:

(27) Saudi

a. Word-medial

kálbạkum 'your-pl dog' Gúmraha 'her age'

Párḍaha 'her land' híbraha — 'its-f ink'

jáwwaha 'its-f weather' Sáddahum 'he counted them'

b. Word-final

híbịir 'ink' kízib 'lying'

šíïir 'poetry' fífil 'deed'

The forms in (27) show a complementarity in the distribution of the epenthetic high and low vowel, with the low vowel occurring in syllables without codas, and the high vowel occurring with codas. In the presence of a coda consonant, only a high vowel may serve as a nucleus. If /a/ has the same default status as /i/, one would expect it to exhibit the same freedom in distribution exhibited by its high counterpart. Thus, we would expect to find a dialect which epenthesizes a low vowel in a closed syllable. Such a dialect has not yet been found. Hence, the following are the attested epenthetic syllable types ascertained so far:

(28)

\section{$\mathrm{CiCa} \quad \mathrm{CiC} * \mathrm{CaC}$}

Moreover, the vowel inventory in Arabic consists of three basic vowels with short and long counterparts: /a/, /i/, and /u/. The phonemic status of short $/ \mathrm{u} /$ is called into question in works by Haddad (1984), Herzallah (1990) and McCarthy (1991, 1994). Based on its limited distribution in emphatic contexts, they argue that $/ \mathrm{u} /$ is an allophonic variant of $/ \mathrm{i} /$ and does not constitute an independent phoneme. Eliminating / $\mathrm{u} /$ from the vowel inventory, we are left with two vowels only, /a/ and /i/; both serving as epenthetic vowels in Saudi. It is illogical to assume that the set

\footnotetext{
14 Nouns corresponding to CVCC nouns in Standard or Egyptian are realized in Sudanese as disyllabic CVCVC in both their basic and inflected forms; e.g., [darib] 'path' and [daribna] 'our path'. This lack of alternation lead Hamid (1984) to posit an underlying CVCVC shape for these nouns, indicating lexicalization of such nominals as disyllabic stems.
} 
of default vowels in a language is coextensive with its vowel inventory.

The asymmetric distribution of epenthetic /i/ and /a/ in Arabic dialects in general, and the complementary distribution of these vowels in Saudi in particular, lend empirical support to the proposal that there may be a correlation between epenthetic vowel quality and syllable type. Depending on their relative strength, syllables may be divided into two types: relatively weak and relatively strong syllables. Open and unstressed syllables are weak relative to their closed and stressed counterparts. In addition, a syllable containing the less sonorous high nucleus is weak relative to a syllable with the more sonorous low nucleus.

(29)

$\begin{array}{ll}\text { Weak } & \text { Strong } \\ \mathrm{CV} & \mathrm{CVC} \\ \mathrm{Ci} & \mathrm{Ca} \\ \mathrm{CV} & \mathrm{CV}\end{array}$

In onset dialects where final consonantality is restricted to stems, the open, hence weak, syllable is the default; we therefore find that two of the onset dialects, Saudi and Sudanese, select a low, hence, strong, vowel to serve as the nucleus of the epenthetic syllable. In Egyptian, the only onset dialect that employs a high epenthetic vowel, the stress system places the epenthetic syllable (always the penultimate syllable) in a strong metrical position. The stressing of the epenthetic vowel is sufficient to strengthen the epenthetic syllable, and therefore obviates the need for a strong low nucleus. In coda dialects, where Final-C favors closed epenthetic syllables, a non-low vowel is always selected to serve as its nucleus. Thus, epenthetic syllables in Arabic dialects encompass all three strong syllable types shown in (29): [CiC], strengthened by the coda consonant, appears in all coda dialects; [Ca], strengthened by the low nucleus, occurs in onset dialects wherein a penultimate open syllable is metrically weak; and [C'], strengthened by stress, occurs in onset dialects where a penultimate syllable is metrically strong regardless of syllable weight. Two epenthetic syllable types are nonexistent: We do not find an ultra-weak epenthetic syllable in onset dialects, i.e., an unstressed [Ci]. Nor do we find an ultra-strong epenthetic syllable in coda dialects, i.e., a syllable with both a low vowel and a coda consonant, $[\mathrm{CaC}]$. Since the quality of the epenthetic vowel is determined by the type of the epenthetic syllable, which in turn is determined by the Final-C Parameter, Final-C is therefore indirectly responsible for the choice of the quality of the epenthetic vowel in each dialect. 


\section{Conclusion}

In this paper, I have proposed that the typological classification of Arabic varieties, previously attributed to the directionality parameter or mora type, is better understood as the consequence of extending Final Consonantality from higher morphological units to lower prosodic ones. While in Classical Arabic, Final-C is limited to stems but not words or syllables, Arabic dialects belong to two major types, onset dialects which limit Final-C to stems and words but not syllables; that is the constraint applies only within the morphological component, and coda dialects where Final-C extends to syllables, thereby applying to prosodic structure as well. The extreme case of Final-C is observed in North African dialects where words, stems, syllables, and moras are consonant final. I have shown that further consequences are derivable from this typology. In particular, the distribution of augmentation and reduction processes seem to correlate directly with the position of the epenthetic vowel, the quality of which is determined by the presence or absence of the extended Final-C constraint.

The motivation behind extending final consonantality to the phonological component in coda dialect we hypothesize is to establish uniformity between morphology and prosody. Morphological categories in Arabic, stems and words, are right-aligned by a consonant, while the universally unmarked (open) syllable is right-aligned by a vowel. By extending Final-C from morphology to prosody in coda languages, both morphological and prosodic categories would maintain uniform consonantal alignment at their right edge. In the absence of Final-C in onset dialects, alignment of morphological and prosodic categories remains asymmetric. Perhaps the restriction of high vowel syncope to one environment (successive unstressed open syllables) in onset dialects may indicate a first step of a transitional stage from onsethood to codahood. This transition may also explain the variation we find in onset dialect despite their small number, vs. the stability of coda dialects despite their large number. If this explanation is accurate, it demonstrates that language change does not necessarily proceed toward simplification, but rather toward uniformity, even at the expense of creating marked structures.

Although the analysis proposed here dichotomizes the typology of dialects into two distinct types, Onset vs. Coda, it is important to emphasize however that dialects do not always exhibit all the expected properties of the type they belong to. As stated in earlier work (see Farwaneh 1995 chapter 6) the Onset and Coda types form a continuum along which dialects may be placed at different points depending on their 
closeness to the ideal Onset or Coda type. Classical Arabic provides an example of the ideal Onset pattern with its onset epenthesis, closedsyllable shortening, prohibition on complex syllables, and absence of open-syllable reduction rules. None of the dialects discussed provides a clear-cut example of the Onset type. Egyptian is the closest prosodically to Classical Arabic, yet the grammar of Egyptian differs from that of Classical Arabic in that it employs a medial syncope rule that eliminates a small number of open syllables. Saudi deviates further from the ideal Onset type: In addition to medial syncope, it generates surface long consonant final CVVC syllables in some environments. Sudanese approaches the Coda boundary by deriving the long-closed CVVC syllable in all environments (cf. beetna). Within the Coda group the variation is more subtle. Iraqi is similar to Sudanese in blocking all potentials for generating complex syllables by epenthesis, it differs only in the position of the epenthetic vowel. The Levantine and Gulf dialects differ from Iraqi in two respects: First, they generalize the domain of syncope, thereby maximizing the number of closed syllables and complex initial syllables. Second, they generalize the application of adjunction which maximizes the number of syllables with complex codas. The result is an increasing number of complex syllables of the shape CVCC and CCVCC in surface representation. These observations are confirmed in Watson (2007) study which, through an examination of new and previously discussed data, further elaborates and expands Kiparsky's typology. Her thorough analysis shows that not all dialects exhibit the eight-feature diagnostics of the Onset/Coda typology Kiparsky proposes. This fact necessitates in her account the postulation of a fourth type labeled as $\mathrm{Cv}$ (with lower case v) to account for apparently Onset dialects with Coda-like characteristics. This hybrid type includes Sudanese, Saudi Makkan and Yemeni. Farwaneh's (1995) observation concerning the stability of Coda dialects vs. the variability of Onset dialects is confirmed by Watson (2007) who states that "VC (Coda) dialects exhibit Kiparsky's predicted phenomena more completely than CV (Onset) dialects (348). The only Onset characteristic exhibited by Coda dialects involves final glottalization or desonorization, which Watson recognizes as an areal rather than syllabification phenomenon (354). These hybrid dialects are not counterexamples to the final consonantality hypothesis but rather confirmation that the Final-C constraint has penetrated the phonology of most Onset dialects transforming them gradually into the pervasive Coda type. 


\section{BIBLIOGRAPHY}

Abu-Mansour, Mahasen. 1987. A Nonlinear Analysis of Arabic Syllabic Phonology with Special Reference to Makkan, $\mathrm{PhD}$ dissertation, University of Florida, Gainesville.

Abu-Mansour, Mahasen. 1990. 'Epenthesis, Gemination and Syllable Structure', Perspectives on Arabic Linguistics I, ed. by Mushira Eid and John McCarthy, 167-191. Amsterdam: John Benjamins.

Abu-Mansour, Mahasen. 1991. 'Epenthesis in Makkan Arabic: Unsyllabified Consonants v. Degenerate Syllables', Perspectives on Arabic Linguistics, II, ed. by Bernard Comrie and Mushira Eid, 137154. Amsterdam: John Benjamins.

Abu-Salim, Isam. 1980. 'Epenthesis and Geminate Consonants in Palestinian Arabic', Studies in the Linguistic Sciences 10/2:1-12.

Al-Tajir, Mahdi Abdallah. 1982. Language and Linguistic Origin in Bahrain, London, Boston: Paul Kegan International.

Archangeli, Diana. 1984. Underspecification in Yawelmani Phonology and Morphology, $\mathrm{PhD}$ dissertation, MIT.

Bat-El, Outi. 1994. 'Stem Modification and Cluster Transfer in Modern Hebrew', Natural Language and Linguistic Theory 12:571-596.

Benmamoun, Elabbas. 1999. 'Arabic Morphology: The Central Role of the Imperfective'. Lingua 108:175-201.

Benmamoun, Elabbas. 2003. 'The Role of the Imperfective Template in Arabic Morphology'. Language Processing and Acquisition in Languages of Semitic Root-based Morphology, Joseph Shimron (ed.), John Benjamins.

Broselow, Ellen. 1976. The Phonology of Egyptian Arabic. PhD dissertation, University of Massachusetts, Amherst.

Broselow, Ellen. 1983. 'Non-obvious Transfer: On Predicting Epenthesis errors'. Language Transfer in Language Learning, S. M. Gass and L. Selinker (eds.), 269-280. Rowley: Newbury House.

Broselow, Ellen. 1992. 'Parametric Variation in Arabic Dialect Phonology', Perspectives on Arabic Linguistics IV, Ellen Broselow, Mushira Eid and John McCarthy (eds.), 7-46. Amsterdam and Philadelphia: John Benjamins.

Eid, M. 1985. 'Linguistic Typology and the Study of Arabic Dialects.' Unpublished manuscript.

Eksell, Kerstin. 1984. 'On Participle Constructions with an N-Element in Some Arabic Dialects'. Studia Orientalia 55/20, 395-409. Finnish Oriental Society: Helsinki.

Erwin, Wallace. 1963. A Short Reference Grammar of Iraqi Arabic. 
Washington: Georgetown University Press.

Farwaneh, Samira. 1995. Directionality Effects in Arabic Dialect Syllable Structure. Ph.D dissertation, University of Utah.

Fischer, Wolfdietrich and Otto Jastrow (eds.). 1980. Handbuch der Arabischen Dialekte. Wiesbaden: Otto Harrassowitz.

Haddad, Ghassan F. 1984. 'Epenthesis and sonority in Lebanese Arabic'. Studies in the Linguistic Sciences 14/1, 57-88.

Hamid, Abdel Halim. 1984. A Descriptive Analysis of Sudanese Colloquial Arabic Phonology. PhD dissertation, University of Illinois, Urbana-Champaign.

Hayes, Bruce. 1989. 'Compensatory Lengthening in Moraic Phonology'. Linguistic Inquiry. 20/2. 255-306.

Herzallah, Ruqayyah. 1990. Aspects of Palestinian Arabic phonology: Anon-linear approach. Ph.D dissertation, Cornell University, Ithaca, New York.

Itô, Junko. 1986. Syllable Theory in Prosodic Phonology. $\mathrm{PhD}$ dissertation, University of Massachusetts, Amherst.

Itô, Junko. 1989. 'A Prosodic Theory of Epenthesis'. Natural Language and Linguistic Theory 7: 217-259.

Kenstowicz, Michael. 1980. 'Notes on Cairene Arabic Syncope'. Studies in the Linguistic Sciences 10: 39-53.

Kiparsky, Paul. 2003. 'Syllables and moras in Arabic', The Syllable in Optimality Theory, Caroline Féry and Ruben van de Vijver (Eds.), 147-182. Cambridge: Cambridge University Press.

Kisseberth, Charles. 1970. 'On the Functional Unity of Phonological Rules', Linguistic Inquiry, 1: 291-306.

Koutsoudas, A., Sanders, G., and C. Noll. 1974. 'On the Application of Phonological Rules', Language 50: 1-28.

McCarthy, John. 1979. 'On Stress and Syllabification.' Linguistic Inquiry. 10/3: 443-465.

McCarthy, John. 1981. 'A Prosodic Theory of Nonconcatenative Morphology'. Linguistic Inquiry 12:373-418.

McCarthy, John. 1986. 'OCP Effects: Gemination and Antigemination'. Linguistic Inquiry. 17/2: 207-263.

McCarthy, John. 1991. 'Guttural phonology'. Perspectives on Arabic linguistics III, ed. by Mushira Eid and Bernard Comrie, xx-xx. Amsterdam and Philadelphia: John Benjamins.

McCarthy, John. 1994. 'The phonetics and phonology of Semitic pharyngeals'. Phonological structure and phonetic form: Papers in laboratory phonology III, ed. by Patricia Keating, 191-233. Cambridge: Cambridge University Press. 
McCarthy, John. 2002. A Thematic Guide to Optimality Theory. Cambridge and New York: Cambridge University Press.

McCarthy, John. and Alan Prince 1990. 'Prosodic Morphology and Templatic Morphology'. Perspectives on Arabic Linguistics. M. Eid and J. McCarthy. Amsterdam, John Benjamins. 2: 1-54.

McOmber, Michael. 1995. 'Morpheme Edges and Arabic Infixation' in Mushira Eid (ed.), Perspectives on Arabic Linguistics, VI, 173-189.

Obrecht, Dean. 1965. 'Three Experiments in the Perception of Geminate Consonants in Arabic'. Language and Speech. 8. 31-41.

Qafisheh, Hamdi. 1977. A Short Reference Grammar of Gulf Arabic. Tucson: University of Arizona Press.

Prince, Allan, and Paul Smolensky. 1993. Optimality Theory. MS, Rutgers University.

Selkirk, Elizabeth. 1981. 'Epenthesis and Degenerate Syllables in Cairene Arabic'. Theoretical Issues in the Grammar of Semitic Languages, ed. by Hagid Borer and Joseph Aoun, 3.209-232. Cambridge, Massachusetts: MIT Department of Linguistics.

Shāban, Kassim Ali. 1977. The Phonology of Omani Arabic, PhD. dissertation, University of Texas, Austin.

Trimingham, J. Spencer. 1946. Sudan Colloquial Arabic. London: Oxford University Press.

Watson, Janet. 2007. 'Syllabification Patterns in Arabic: Long segments and mora sharing', Phonology 24/2, 335-56. 